\title{
Necrotizing fasciitis: epidemiology and clinical predictors for amputation
}

This article was published in the following Dove Press journal:

International Journal of General Medicine

14 May 2015

Number of times this article has been viewed

\section{Patcharin Khamnuan ${ }^{1,2}$ \\ Wilaiwan Chongruksut ${ }^{3}$ \\ Kijja Jearwattanakanok ${ }^{4}$ Jayanton Patumanond ${ }^{5}$ Apichat Tantraworasin ${ }^{3}$}

'Clinical Epidemiology Program, Faculty of Medicine, Chiang Mai University, Chiang Mai, ${ }^{2}$ Department of Nursing, Phayao Hospital, Phayao, ${ }^{3}$ Department of Surgery, Faculty of Medicine, Chiang Mai University, ${ }^{4}$ Department of Surgery, Nakornping Hospital, Chiang Mai, ${ }^{5}$ Clinical Epidemiology Unit, Clinical Research Center, Faculty of Medicine, Thammasat University, Pathum Thani, Thailand
Correspondence: Apichat Tantraworasin Department of Surgery, Faculty of Medicine, Chiang Mai University, II 0 Intawaroros Road, Meuang District, Chiang Mai 50200, Thailand

Tel +6653945767

Fax +665394 6139

Email ohm_med@hotmail.com
Background: Necrotizing fasciitis, a relatively uncommon infection involving the skin, subcutaneous tissue, and fascia, is a rapidly progressive soft tissue infection and a medical and surgical urgency. Delayed debridement, with subsequent huge soft tissue loss is associated with loss of limb and infection and is the most common cause of mortality. The purpose of this work is to describe the epidemiology of necrotizing fasciitis and to identify the clinical characteristics that may be used to predict amputation in routine clinical practice.

Methods: Retrospective cohort study data were collected from three general hospitals located in the Chiang Rai, Kamphaeng Phet, and Phayao provinces in northern Thailand. Epidemiologic data for all patients with a surgically confirmed diagnosis of necrotizing fasciitis between 2009 and 2012 were collected. Medical records and reviews were retrieved from inpatient records, laboratory reports, and registers. Clinical predictors for amputation were analyzed by multivariable risk regression.

Results: A total of 1,507 patients with a diagnosis of necrotizing fasciitis were classified as being with amputation $(n=127,8.4 \%)$ and without amputation $(n=1,380,91.6 \%)$. The most common causative Gram-positive and Gram-negative pathogens were Streptococcus pyogenes (33.3\% in the amputation group and $40.8 \%$ in the non-amputation group) and Escherichia coli (25\% in the amputation group and $17.1 \%$ in the non-amputation group). Predictive factors for amputation included gangrene (risk ratio [RR] 4.77, 95\% confidence interval [CI] 2.70-8.44), diabetes mellitus (RR 3.08, 95\% CI 1.98-4.78), skin necrosis (RR 2.83, 95\% CI 2.52-3.18), soft tissue swelling (RR 1.76, 95\% CI 1.24-2.49), and serum creatinine values $\geq 1.6 \mathrm{mg} / \mathrm{dL}$ on admission (RR 1.71, 95\% CI 1.38-2.12). All data were analyzed using the multivariable risk regression generalized linear model.

Conclusion: The most causative pathogens were $S$. pyogenes and E. coli. Clinical predictors for amputation in patients with necrotizing fasciitis included having diabetes mellitus, soft tissue swelling, skin necrosis, gangrene, and serum creatinine values $\geq 1.6 \mathrm{mg} / \mathrm{dL}$ on admission. Thus, patients with any of these predictors should be monitored closely for progression and receive early aggressive treatment to avoid limb loss.

Keywords: necrotizing fasciitis, clinical predictors, amputation

\section{Introduction}

Necrotizing fasciitis (NF) is a serious form of infection involving rapidly spreading inflammation and extensive necrosis of the skin, subcutaneous tissue, and superficial fascia. ${ }^{1}$ The treatment of choice for NF is rapid surgical debridement and broad spectrum antibiotic therapy. ${ }^{2}$ Delayed treatment may result in extensive loss of soft tissue associated with limb loss; moreover, the risk of mortality is also increased. ${ }^{3}$ 
The reported prevalence of mortality and limb loss associated with NF is $15 \%-29 \%{ }^{4,5}$ and $20.3 \%-26 \%,{ }^{6,7}$ respectively. In Thailand, reported amputation and mortality rates are $8.7 \%-15.4 \%{ }^{8,9}$ and $5.9 \%-22.1 \%{ }^{8,9}$ respectively.

The early stages of the disease are often misdiagnosed as cellulitis or abscess because of the absence of specific clinical features. When diagnosis is delayed or the severity of the disease is unidentified, mortality or morbidity such as limb loss might occur. ${ }^{3,10}$ Thus, identifying specific characteristic evidence and early diagnosis followed by rapid treatment are important to reduce amputation and mortality rates. ${ }^{2}$

In the past, only a few studies have demonstrated the risk factors associated with increased amputation in NF. In a study of 80 patients with NF, Dworkin et $\mathrm{al}^{4}$ found that independent predictors of limb loss included being female, having diabetic mellitus (DM), presence of cutaneous gangrene on admission, and evidence of underlying conditions. Anaya et $\mathrm{al}^{6}$ reviewed $166 \mathrm{NF}$ patients and showed that a history of heart disease, shock at hospital admission (systolic blood pressure $<90 \mathrm{mmHg}$ ), and clostridial infection were independent predictors of limb loss in NF patients. Unfortunately, all these studies had small sample sizes and widely varying patient populations.

The purpose of this study was to examine the epidemiologic features and explore clinical risk characteristics for amputation in NF patients that could be used in a routine clinical practice. The findings may be applied in clinical evaluation, raise awareness, and help in the prevention of disease complications to reduce the risk of limb loss.

\section{Patients and methods}

Eligible patients were registered and treated at three general hospitals located in the Chiang Rai, Kamphaeng Phet, and Phayao provinces in northern Thailand. Medical records between January 2009 and December 2012 were collected for patients with a diagnosis of NF. The diagnoses were established by findings at the time of surgery. Our institution follows the Infection Diseases Society of America practice guidelines for the diagnosis and management of skin and soft tissue infection. ${ }^{11}$ The diagnosis is normally obvious on gross inspection without a need for pathologic confirmation. When suspicion is sufficient to warrant a biopsy, the diagnosis can be made by frozen section analysis. The definition of NF is the subcutaneous tissue and fascia necrosis involving the skin and muscle identified in the operating room., ${ }^{3,12}$

All patients were assessed by emergency physicians as soon as they were admitted to the emergency room. They received broad spectrum antibiotics covering anaerobic and aerobic bacterial organisms and early surgical debridement after the diagnosis was made. Pus culture or tissue culture was performed in occasional cases. Anaerobic bacterial culture was not performed because of unavailability of culture medium. Micro-organisms in blood and wound culture were cultured in some patients upon request by the surgeon. Amputation sites included fingers and toes, hands and forearms, and below and above the knee.

This was a retrospective cohort study with a prognostic research design. The data were obtained from inpatient records, laboratory reports, and registered data. In all, characteristics for 1,507 patients were examined for the first day of admission and after 48-72 hours, including demographic data, clinical manifestations, vital signs, laboratory findings, treatment, outcomes, and discharge status.

Analysis of demographic and clinical data was performed using descriptive statistics and compared between patients with and without amputation. Categorical variables were expressed as the count and percentage and analyzed by Fisher's Exact test. Continuous variables were expressed as the mean and standard deviation and analyzed using the Student's $t$-test or Mann-Whitney $U$ test depending on data distribution.

Step backward multivariable risk regression analyses were used to obtain the independent predictive factors for amputation and are shown with the risk ratio (RR) and 95\% confident interval (CI). All variables with $P<0.05$ from univariable analysis or significant clinical variables were included in the multivariable analysis model, with $P<0.05$ indicating statistical significance. The study was approved by the ethics committee of the Faculty of Medicine, Chiang Mai University, and Chiang Rai Prachanukroh hospital.

\section{Results}

A total of 1,507 eligible patients with a diagnosis of NF were enrolled in this study, and classified in two groups, ie, an amputation group (127 patients, 8.4\%) and a nonamputation group (1,380 patients, 91.6\%). The incidence of NF in this cohort was 15.5 cases per 100,000 population in the Chiang Rai, Kamphaeng Phet, and Phayao provinces. The male to female ratio was $1.3: 1$ and the mean age was $60.1 \pm 14.9$ (range 2-95) years between 2009 and 2012. The incidence of amputation was $8.4 \%$. The number of patients with amputation was 127 (8.4\%). The most common sites of amputation were fingers/toes (44.1\%) and above the knee $(22.8 \%)$ as shown in Table 1.

Microbiological data regarding blood and wound cultures are shown in Table 2. Blood cultures were done in 
Table I Site of amputation in 127 patients with necrotizing fasciitis

\begin{tabular}{ll}
\hline Site of amputation & $\mathbf{n}(\%)$ \\
\hline Finger/toes & $56(44.1)$ \\
Above knee & $29(22.8)$ \\
Below knee & $26(20.5)$ \\
Forefoot & $11(8.7)$ \\
Hand and forearm & $5(3.9)$ \\
\hline
\end{tabular}

Note: Values are shown as $n(\%)$.

$429(28.5 \%)$ of 1,505 patients. In all, 73 patients $(17.0 \%)$ were found to have positive isolates and $356(83.0 \%)$ were reported as having no bacteria seen. Wound cultures were done in $730(48.5 \%)$ of 1,506 patients; 470 patients had positive isolated specimens (64.4\%) and 260 patients had a negative wound culture (35.6\%). Only blood culture was carried out in 146 patients $(9.7 \%)$, only wound culture was carried out in 447 patients (29.7\%), and both blood and wound cultures were carried out in 283 patients $(18.8 \%)$. Total cultures were performed in 876 patients $(58.2 \%)$. Data for blood culture in two patients and for wound culture in one patient were missing from the medical records. The number of patients infected with multiple pathogens on blood culture and wound culture comprised six patients $(8.6 \%)$ and 85 patients $(19.0 \%)$, respectively. The most common causative Gram-positive pathogen from wound culture was Streptococcus pyogenes in both the amputation group $(14.9 \%)$ and the non-amputation group (17.4\%). However,

Table 2 Micro-organisms in blood and wound cultures in patients with necrotizing fasciitis with amputation and without amputation*

\begin{tabular}{|c|c|c|c|c|}
\hline \multirow[t]{2}{*}{ Organism } & \multicolumn{2}{|c|}{ Amputation } & \multicolumn{2}{|c|}{ Non-amputation } \\
\hline & Blood & Wound & Blood & Wound \\
\hline \multicolumn{5}{|l|}{ Gram-positive } \\
\hline Streptococcus pyogenes & $0(0.0)$ & II (I4.9) & II (2.8) & $113(17.4)$ \\
\hline Staphylococcus aureus & $0(0.0)$ & $9(12.0)$ & $5(1.3)$ & $81(12.4)$ \\
\hline $\begin{array}{l}\text { Coagulase-negative } \\
\text { staphylococcus }\end{array}$ & I (2.7) & $4(5.4)$ & II (2.8) & $22(3.4)$ \\
\hline Staphylococcus epidermidis & I (2.7) & $0(0.0)$ & $7(1.8)$ & $9(1.4)$ \\
\hline Staphylococcus saprophyticus & I (2.7) & $0(0.0)$ & $2(0.5)$ & II (I.7) \\
\hline Streptococcus pneumoniae & $0(0.0)$ & $0(0.0)$ & $\mathrm{I}(0.3)$ & $3(0.5)$ \\
\hline Other Gram-positive & I (2.7) & $5(6.8)$ & $9(2.3)$ & $18(2.8)$ \\
\hline \multicolumn{5}{|l|}{ Gram-negative } \\
\hline Escherichia coli & $0(0.0)$ & I3 (I7.5) & $6(1.5)$ & $37(5.7)$ \\
\hline Acinetobacter spp. & $0(0.0)$ & $5(6.7)$ & $3(0.8)$ & $34(5.2)$ \\
\hline Stenotrophomonas spp. & $0(0.0)$ & $\mathrm{I}(\mathrm{I} .3)$ & $\mathrm{I}(0.3)$ & $\mathrm{I}(0.2)$ \\
\hline Salmonella spp. & I (2.8) & I (I.4) & $\mathrm{I}(0.3)$ & $0(0.0)$ \\
\hline Citrobacter spp. & I (2.7) & $4(5.3)$ & $\mathrm{I}(0.3)$ & $14(2.2)$ \\
\hline Other Gram-negative & $0(0.0)$ & $26(35.1)$ & $17(4.4)$ & $101(15.6)$ \\
\hline
\end{tabular}

Notes: *Micro-organisms in blood and wound culture did not show statistically significant differences between the two groups $(P>0.05)$. Values are shown as $n(\%)$. from blood culture, this pathogen was found in only $2.8 \%$ of the non-amputation group and not found at all in the amputation group. The total percentages of $S$. pyogenes infection in the amputation and non-amputation groups were $33.3 \%$ and $40.8 \%$, respectively. The most common causative Gramnegative pathogen from wound culture in the amputation (17.5\%) and non-amputation groups (5.7\%) was Escherichia coli; however, from blood culture, this pathogen was found in only $1.5 \%$ of the non-amputation group and not found at all in the amputation group. The total percentages of $E$. coli infection in the amputation and non-amputation groups were $25 \%$ and $17.1 \%$, respectively. No significant pathogen infection was observed in either group $(P>0.05)$.

Patient demographic and clinical characteristics, including sex, underlying disease such as DM, wound appearance such as skin necrosis, gangrene, creatinine level, fasciotomy, severe sepsis, and length of hospital stay showed statistically significant differences between the two groups (see Tables 3 and 4). The numbers of patients who had DM, necrosis, or gangrene in the amputation group were significantly higher than those in the non-amputation group $(P<0.001)$. Serum creatinine on admission and within 48-72 hours after admission in the amputation group was significantly higher than in the non-amputation group. Random blood sugar values were found in only 226 patients from medical records, and the mean blood sugar value at the time of admission in the non-amputation group was lower than that in the amputation group $(125.9 \pm 60.1 \mathrm{mg} / \mathrm{dL}$ versus $204.5 \pm 124.7 \mathrm{mg} / \mathrm{dL}$, $P<0.001$ ) by univariable analysis. However, in multivariable analysis, the random blood sugar level was not a risk factor of amputation. The blood sugar value at $48-72$ hours was not available in this study. Other laboratory findings and vital signs did not differ significantly between the two groups.

All significant variables (with $P<0.05$ ) and clinical characteristics, such as age and soft tissue swelling, were included in the multivariable analysis model. Step backward multivariable risk regression analysis generalized linear models after controlling the characteristics differences among the hospital records. Moreover, adjusting for sex and age in the model demonstrated that the independent clinical predictors for amputation in NF patients included having DM (RR 3.08, 95\% CI 1.98-4.78, $P<0.001$ ), soft tissue swelling (RR 1.76, 95\% CI 1.24-2.49, $P=0.001$ ), skin necrosis (RR $2.83,95 \%$ CI $2.52-3.18, P<0.001$ ), gangrene (RR 4.77, 95\% CI 2.70-8.44, $P<0.001$ ), and serum creatinine values $\geq 1.6 \mathrm{mg} / \mathrm{dL}$ on admission (RR 1.71, 95\% CI 1.38-2.12, $P<0.001)$ as shown in Table 5. 
Table 3 Demographic characteristics and clinical manifestations in I,507 patients with necrotizing fasciitis (with amputation and without amputation)

\begin{tabular}{|c|c|c|c|}
\hline Characteristics & $\begin{array}{l}\text { Amputation } \\
(n=\mid 27)\end{array}$ & $\begin{array}{l}\text { Non- } \\
\text { amputation } \\
(n=I, 380)\end{array}$ & $P$-value \\
\hline Sex & & & 0.039 \\
\hline Male & $60(47.2)$ & $788(57.1)$ & \\
\hline Female & $67(52.8)$ & $591(42.9)$ & \\
\hline Age (years) & & & 0.114 \\
\hline$<60$ & $54(42.9)$ & $690(50.4)$ & \\
\hline$\geq 60$ & $72(57.1)$ & $678(49.6)$ & \\
\hline BMI & & & 0.550 \\
\hline$\leq 18.50$ & $21(18.1)$ & $176(14.4)$ & \\
\hline$|8.5|-29.99$ & $87(75.0)$ & $954(78.0)$ & \\
\hline$\geq 30.00$ & $8(6.9)$ & $93(7.6)$ & \\
\hline Education & & & 0.402 \\
\hline No education & $60(47.2)$ & $592(43.0)$ & \\
\hline Primary education & $59(46.5)$ & $704(5 I .1)$ & \\
\hline Secondary education & $4(3.2)$ & $58(4.2)$ & \\
\hline $\begin{array}{l}\text { Bachelor's degree } \\
\text { and more }\end{array}$ & $4(3.1)$ & $23(1.7)$ & \\
\hline Occupation & & & 0.353 \\
\hline $\begin{array}{l}\text { Elderly who stay } \\
\text { at home }\end{array}$ & $64(50.4)$ & $635(46.0)$ & \\
\hline Farmers/laborers & $55(43.3)$ & $678(49.2)$ & \\
\hline Officials & $8(6.3)$ & $66(4.8)$ & \\
\hline \multicolumn{4}{|l|}{ Underlying morbidity } \\
\hline Diabetes & $74(58.3)$ & $313(22.7)$ & $<0.001$ \\
\hline Heart disease & $12(9.5)$ & $84(6.1)$ & 0.180 \\
\hline Renal disease & $5(3.9)$ & $40(2.9)$ & 0.423 \\
\hline Cirrhosis & $2(1.6)$ & $59(4.3)$ & 0.163 \\
\hline Hypertension & $51(40.2)$ & $487(35.3)$ & 0.288 \\
\hline Gout & $8(6.3)$ & $139(10.1)$ & 0.211 \\
\hline Chronic alcoholism & $13(10.2)$ & $219(15.9)$ & 0.096 \\
\hline \multicolumn{4}{|l|}{ Wound appearance } \\
\hline Soft tissue swelling & $109(85.8)$ & $\mathrm{I}, 134(82.2)$ & 0.311 \\
\hline Erythema & $73(57.5)$ & $701(50.8)$ & 0.164 \\
\hline Bleb & $48(37.8)$ & $603(43.7)$ & 0.224 \\
\hline Skin necrosis & $64(50.4)$ & $339(24.6)$ & $<0.001$ \\
\hline Gangrene & $18(14.2)$ & $19(1.4)$ & $<0.001$ \\
\hline Severe pain & $109(85.8)$ & $\mathrm{I}, 207(87.5)$ & 0.577 \\
\hline Site of wound & & & 0.158 \\
\hline Head and neck & $0(0.0)$ & $8(0.6)$ & \\
\hline Trunk & $0(0.0)$ & $28(2.0)$ & \\
\hline Upper limb & $16(12.6)$ & $260(18.8)$ & \\
\hline Lower limb & $107(84.2)$ & $1,054(76.4)$ & \\
\hline Fournier's gangrene & $0(0.0)$ & $5(0.4)$ & \\
\hline Multiple site & $4(3.2)$ & $25(1.8)$ & \\
\hline Hospital & & & 0.070 \\
\hline Chiang Rai & $58(45.7)$ & $759(55.0)$ & \\
\hline Kamphaeng Phet & $59(46.4)$ & $498(36.1)$ & \\
\hline Phayao & $10(7.9)$ & $123(8.9)$ & \\
\hline
\end{tabular}

Note: Values are shown as $\mathrm{n}(\%)$.

Abbreviation: BMI, body mass index.

\section{Discussion}

This study investigated clinical characteristics that could serve as independent predictors for amputation in patients with NF in routine clinical practice. Our results should indicate the ways and means for early recognition of NF, with the focus on
Table 4 Laboratory findings, vital signs, and outcomes of treatment in I,507 patients with necrotizing fasciitis comparing between amputation and non-amputation group

\begin{tabular}{|c|c|c|c|}
\hline Characteristics & $\begin{array}{l}\text { Amputation } \\
(n=127)\end{array}$ & $\begin{array}{l}\text { Non- } \\
\text { amputation } \\
(n=I, 380)\end{array}$ & $P$-value \\
\hline \multicolumn{4}{|l|}{ Laboratory on admission } \\
\hline WBC $\left(\right.$ per $\left.\mathrm{mm}^{3}\right)$ & $18,081.9 \pm 10,187.1$ & $16,794.0 \pm 9,042.9$ & 0.109 \\
\hline PMN (\%) & $82.6 \pm 11.7$ & $82.0 \pm 12.2$ & 0.596 \\
\hline $\begin{array}{l}\text { Creatinine } \\
(\mathrm{mg} / \mathrm{dL})\end{array}$ & $2.3 \pm 1.9$ & $1.9 \pm 1.5$ & 0.019 \\
\hline $\begin{array}{l}\text { Bicarbonate } \\
\text { (mmol/L) }\end{array}$ & $21.8 \pm 5.8$ & $21.7 \pm 5.1$ & 0.822 \\
\hline $\begin{array}{l}\text { Total protein } \\
\text { (g/dL) }\end{array}$ & $6.5 \pm 1.2$ & $6.3 \pm 1.1$ & 0.230 \\
\hline Blood sugar & $204.5 \pm 124.7$ & $|25.9 \pm 60|$. & $<0.001$ \\
\hline \multicolumn{4}{|c|}{ Laboratory $48-72$ hours } \\
\hline WBC $\left(\right.$ per $\left.\mathrm{mm}^{3}\right)$ & $|5| 7 \mid, .6 \pm 7,936.2$ & $14,425.1 \pm 8,168.2$ & 0.291 \\
\hline PMN (\%) & $80.1 \pm 14.8$ & $78.5 \pm 14.7$ & 0.444 \\
\hline Creatinine (mg/dL) & $2.4 \pm 2.2$ & $2.2 \pm 1.8$ & 0.929 \\
\hline $\begin{array}{l}\text { Bicarbonate } \\
\text { (mmol/L) }\end{array}$ & $25.6 \pm 4.5$ & $22.1 \pm 13.8$ & 0.386 \\
\hline $\begin{array}{l}\text { Total protein } \\
(\mathrm{g} / \mathrm{dL})\end{array}$ & $5.7 \pm 1.1$ & $5.6 \pm 1.2$ & 0.906 \\
\hline Blood sugar (mg/dL) & NA & NA & NA \\
\hline \multicolumn{4}{|l|}{ Vital signs on admission } \\
\hline $\begin{array}{l}\text { Body } \\
\text { temperature }\left({ }^{\circ} \mathrm{C}\right)\end{array}$ & $37.3 \pm 0.9$ & $37.3 \pm 0.9$ & 0.997 \\
\hline Pulse (per minute) & $90.0 \pm 15.2$ & $91.5 \pm 16.1$ & 0.302 \\
\hline $\begin{array}{l}\text { Respiratory rate } \\
\text { (per minute) }\end{array}$ & $20.3 \pm 2.4$ & $20.1 \pm 3.9$ & 0.714 \\
\hline $\begin{array}{l}\text { Systolic BP } \\
(\mathrm{mmHg})\end{array}$ & $119.2 \pm 25.2$ & $117.0 \pm 24.2$ & 0.328 \\
\hline $\begin{array}{l}\text { Diastolic BP } \\
(\mathrm{mmHg})\end{array}$ & $70.0 \pm 14.7$ & $70.2 \pm 14.7$ & 0.891 \\
\hline \multicolumn{4}{|l|}{ Vital signs $48-72$ hours } \\
\hline $\begin{array}{l}\text { Body } \\
\text { temperature }\left({ }^{\circ} \mathrm{C}\right)\end{array}$ & $37.2 \pm 0.8$ & $37.3 \pm 0.8$ & 0.394 \\
\hline Pulse (per minute) & $89.1 \pm 14.9$ & $87.6 \pm \mid 4.1$ & 0.275 \\
\hline $\begin{array}{l}\text { Respiratory rate } \\
\text { (per minute) }\end{array}$ & $19.3 \pm 4.3$ & $19.5 \pm 4.2$ & 0.710 \\
\hline Systolic BP (mmHg) & $121.2 \pm 19.5$ & $120.6 \pm 17.5$ & 0.723 \\
\hline $\begin{array}{l}\text { Diastolic BP } \\
(\mathrm{mmHg})\end{array}$ & $73.3 \pm 12.2$ & $73.1 \pm 11.2$ & 0.849 \\
\hline Severe sepsis & $32(25.2)$ & $207(15.5)$ & 0.008 \\
\hline \multicolumn{4}{|l|}{ Discharge status } \\
\hline Alive & $97(100.0)$ & I, I06 (98.9) & 0.614 \\
\hline Referred & $0(0.0)$ & $12(1.1)$ & \\
\hline \multicolumn{4}{|l|}{ Dead } \\
\hline Dead in hospital & $28(100.0)$ & $24 I(92.0)$ & 0.240 \\
\hline $\begin{array}{l}\text { 28-day mortality } \\
\text { at home }\end{array}$ & $0(0.0)$ & $21(8.0)$ & \\
\hline $\begin{array}{l}\text { Length of hospital } \\
\text { stay (days) }\end{array}$ & $17.5 \pm 22.9$ & $10.7 \pm 11.1$ & $<0.001$ \\
\hline
\end{tabular}

Note: Values are shown as the mean \pm standard deviation or $n(\%)$.

Abbreviations: BP, blood pressure; WBC, white blood cell count; PMN, polymorphonuclear cell or neutrophils; NA, not available.

limb preservation. The 1,507 patients reviewed over 4 years in our study represent a relatively large patient population with NF from several hospitals in northern Thailand. The amputation rate for NF in this study was 8.4\% (127 patients), which is less than in previous reports. ${ }^{4,8}$ The main occupations of 
Table 5 Independent predictor of amputation in 1,507 patients with necrotizing fasciitis using a multivariable analysis generalized linear model adjusted by sex and age

\begin{tabular}{llll}
\hline Risk factors & RR & $\mathbf{9 5 \%} \mathbf{C l}$ & P-value \\
\hline Gangrene & 4.77 & $2.70-8.44$ & $<0.00 \mathrm{I}$ \\
Diabetes & 3.08 & $1.98-4.78$ & $<0.00 \mathrm{I}$ \\
Skin necrosis & 2.83 & $2.52-3.18$ & $<0.00 \mathrm{I}$ \\
Soft tissue swelling & 1.76 & $1.24-2.49$ & $0.00 \mathrm{I}$ \\
Creatinine $\geq \mathrm{I} .6 \mathrm{mg} / \mathrm{dL}$ & $\mathrm{I} .7 \mathrm{I}$ & $\mathrm{I} .38-2.12$ & $<0.00 \mathrm{I}$ \\
\hline
\end{tabular}

Abbreviations: $\mathrm{RR}$, risk ratio; $\mathrm{Cl}$, confidence interval.

people in northern Thailand are farming and laboring which were associated with low education and poor hygiene and prone to develop serious soft tissue infection or necrotizing fasciitis. These making NF is a common infectious disease in this area. Moreover, $58.3 \%$ of patients in amputation group have DM and data from multivariable analysis demonstrated that DM is one of predictive factors of amputation, like previous studies. ${ }^{9,13}$ Therefore, treatment with broad-spectrum antibiotics and surgical debridement should be undertaken as early as possible, along with intentional control of blood glucose during the perioperative period to decrease the amputation rate.

The most common causative Gram-positive and Gramnegative pathogens in our study were S. pyogenes and E. coli, respectively. This finding is similar to previous reports., ${ }^{4} 14$ Anaya et $\mathrm{al}^{6}$ reported that clostridial infections were associated with amputation. However, anaerobic bacteria cultures, including for clostridial infection, were not performed in our study because of limitations of the culture process, and the data on organisms were collected from provincial hospitals rather than a tertiary center. Further, only $51.2 \%$ of patients had wound cultures and only $71.5 \%$ had blood cultures. Although we have normal practice guidelines for specimen cultures, some surgeons did not follow these guidelines. Therefore, we did not exactly identify the most common organism causing NF in northern Thailand. The amputation rate for NF patients in each hospital did not differ. The health care systems in the provincial hospitals are the same.

NF is a deadly and rapidly progressive disease. ${ }^{10,12,15}$ Treatment of NF includes early surgical debridement and broad-spectrum antibiotics. ${ }^{2,16-18}$ Thus, awareness of the clinical characteristics of the individual patient could benefit early diagnosis and surgical intervention to reduce the morbidity of NF.

Our study identified clinical characteristics and independent predictors for amputation, including diabetes, soft tissue swelling, skin necrosis, gangrene, and serum creatinine values $\geq 1.6 \mathrm{mg} / \mathrm{dL}$ on admission. Previous studies found that being female, having DM, cutaneous gangrene noted on admission, evidence of an underlying condition, clostridial infection, heart disease, and shock (systolic blood pressure $<90 \mathrm{mmHg}$ ) at hospital admission were independent predictors for limb loss in patients with NF. ${ }^{4,6}$

Our finding that DM was related to limb loss is consistent with that of a previous study reported by Dworkin et al. ${ }^{4}$ However, some studies found that although DM was the most frequent comorbidity in NF patients, it did not significantly increase amputation or mortality rates. ${ }^{6,14,19} \mathrm{DM}$ was also the most common comorbidity in our patients, as reported by other investigators. ${ }^{2,10,13,17,20}$ The pathophysiology of DM is related to the worst outcomes of NF because hyperglycemia induces bacterial growth and tissue ischemia as a result of peripheral vascular disease, leading to amputation..$^{21}$ Patients with DM often develop severe atherosclerosis. The atherosclerotic changes occurring in the limb vessels were found to be more extensive in small-caliber arteries and to result in ischemia and gangrene, ultimately leading to amputation..$^{22}$ However, nearly $45 \%$ of amputation sites involved fingers or toes, and we could not clearly distinguish wet gangrene of the DM foot from NF, which sometimes occur simultaneously.

NF presenting with skin necrosis and gangrene at the time of diagnosis was found to be significantly predictive for amputation in our study $(P<0.001)$. Dworkin et al ${ }^{4}$ similarly reported that cutaneous gangrene presenting on admission was significantly $(P=0.005)$ associated with increased risk of limb loss. In previous studies, the presence of skin necrosis and gangrene were observed in late-stage NF and were the leading causes of an adverse outcome..$^{3,9,23-26}$ As in other previous studies, ${ }^{8,18,19}$ we found that soft tissue swelling of the affected area was a common clinical manifestation in most patients with NF. Infection spreading into the lymphatic and vascular systems is a cause of tissue edema and muscle necrosis, and skin necrosis will occur consequent to thrombosis of microvascular vessels and dysfunction of the nerve supply. ${ }^{27}$ Gangrene is a necrosis of the tissue caused by lack of blood supply. Whenever gangrene was presented, debridement or amputation was needed depending on extension of necrotic areas. ${ }^{22}$

Our study found that serum creatinine values $\geq 1.6 \mathrm{mg} / \mathrm{dL}$ posed an increased risk for limb loss. Higher serum creatinine levels reflect renal dysfunction, presumably associated with septic shock. Anaya et $\mathrm{al}^{6}$ reported that shock (systolic blood pressure $<90 \mathrm{mmHg}$ ) at admission was an independent predictor for limb loss, raised creatinine level and higher mortality similar to many previous studies. ${ }^{14,23,28}$ However, a study report by Dos Santos et $\mathrm{al}^{29}$ did not find serum creatinine levels to be associated with major amputation. 
Their study reported that patients with DM were at high risk for amputation, and that preoperative glycemic control prevented major amputations. Thus, fasting blood sugar should be controlled at $90-130 \mathrm{mg} / \mathrm{dL}$, and blood sugar must be monitored before, during, and after surgery. ${ }^{30}$ Better outcomes were described in patients with all random blood glucose levels $<200 \mathrm{mg} / \mathrm{dL} .{ }^{30}$ General surgical patients with a blood glucose value $>220 \mathrm{mg} / \mathrm{dL}$ had a higher rate of infection. ${ }^{31}$ In NF patients with DM, poor blood glucose control was associated with a poor outcome of treatment. ${ }^{32,33}$ A study from Turkey ${ }^{34}$ reported that the mean blood glucose levels in NF patients who died were significantly higher than those in patients who survived $(195.6 \pm 41.5 \mathrm{mg} / \mathrm{dL}$ versus $133.7 \pm 22.1 \mathrm{mg} / \mathrm{dL}, P=0.040)$. In our study, the random blood sugar value did not appear to be a risk factor of amputation; however, due to missing data, random blood sugar values were available for only $17.7 \%$ of all patients. The serum creatinine level is also important, and we found that elevated creatinine levels on admission were associated with an increased risk of amputation. Acute renal injury is a possible complication of rhabdomyolysis caused by trauma, tissue necrosis, and additional ischemia reperfusion injury. However, rhabdomyolysis associated with acute renal failure often leads to rapidly increasing serum creatinine levels. ${ }^{35}$ Patients with increased serum creatinine levels should be investigated to evaluate the prognosis and optimize planning of treatment and care. Intravenous fluids must be administered very quickly, and fluid intake should be controlled or a nephrologist should be consulted to perform dialysis immediately. ${ }^{36}$

Our review of the literature revealed that both lower body mass index and obesity can increase the risk of infection. ${ }^{37}$ However, amputation rate correlated with body mass index or obesity was not reported. The univariable analysis in our study demonstrated that body mass index was not a risk factor for amputation $(P=0.550)$.

Antibiotic resistance is one of the most important prognostic factors affecting the clinical outcome in patients with NF. Stevens et al reported on the problematic emerging antibiotic resistance involving $S$. pyogenes (erythromycin resistance) and methicillin-resistant Staphylococcus aureus (MRSA). Both of these organisms were associated with adverse outcomes of treatment. Culture results were very important for selection of the appropriate antibiotic. ${ }^{38}$ Our study did not address this issue due to lack of relevant medical records. Most antibiotic resistance data were incomplete, so these data were omitted.

A previous study reported that smoking reduced blood oxygen levels by decreasing blood flow to the tissues and reducing immune system function; both of these mechanisms were considerable risk factors for bacterial infection. ${ }^{39}$ Although cigarette smoking has not been shown to be a significant risk factor for MRSA related to NF, it was associated with a poor outcome. ${ }^{40}$ In our study, smoking status could not be assessed due to missing data in the medical records.

More recently, a marker scoring system based on laboratory risk indicators for NF, ie, C-reactive protein, total white cell count, hemoglobin, serum sodium, serum creatinine, and serum glucose levels on admission was suggested by Wong et al for classification of the severity of $\mathrm{NF}^{41}$ The APACHE (Acute Physiology and Chronic Health Evaluation) II score, a disease severity classification system developed by Knaus et al, ${ }^{42}$ can also be used to evaluate disease severity and describe the morbidity of a patient admitted to intensive care. Unfortunately we could not use either of these scoring systems because of limitations in laboratory testing in the provincial hospital setting. For example, C-reactive protein was not examined in all patients.

Another limitation of this study was its retrospective nature, and some important data could have been omitted due to a lack of medical records. On the other hand, the results of this study might be useful in clinical practice when caring for NF patients in provincial hospitals. We are also concerned about the organisms causing NF. It is possible that our findings could reflect the weakness of the health care system, and they could be used to encourage our government so our findings can be applied in general practice in other countries for a specific regional population, and physicians can use these risk factors to evaluate their patients despite limited resources at local hospitals, as is current practice in developing countries.

\section{Conclusion}

Clinical predictors for limb loss in patients suspected of NF included having DM, soft tissue swelling, skin necrosis, gangrene, and serum creatinine values $\geq 1.6 \mathrm{mg} / \mathrm{dL}$ on admission. Thus, patients presenting any such clinical predictors should be aware of the risk of the disease progressing to amputation and attending health professionals should attempt to resolve these predictive factors as much as possible to decrease morbidity and mortality.

\section{Acknowledgments}

This study was supported by a grant from the Faculty of Medicine and the Graduate School, Chiang Mai University, Chiang Mai, Thailand. The authors wish to thank the authorities 
of Chiang Rai Prachanukroh Hospital, Kamphaeng Phet Hospital, and Phayao Hospital for their support.

\section{Disclosure}

The authors report no conflicts of interest in this work.

\section{References}

1. Wong CH, Chang HC, Pasupathy S, Khin LW, Tan JL, Low CO. Necrotizing fasciitis: clinical presentation, microbiology, and determinants of mortality. J Bone Joint Surg Am. 2003;85A(8):1454-1460.

2. Headley AJ. Necrotizing soft tissue infections: a primary care review. Am Fam Physician. 2003;68(2):323-328.

3. Wong $\mathrm{CH}$, Wang YS. The diagnosis of necrotizing fasciitis. Curr Opin Infect Dis. 2005;18(2):101-106.

4. Dworkin MS, Westercamp MD, Park L, McIntyre A. The epidemiology of necrotizing fasciitis including factors associated with death and amputation. Epidemiol Infect. 2009;137(11):1609-1614.

5. McHenry CR, Piotrowski JJ, Petrinic D, Malangoni MA. Determinants of mortality for necrotizing soft-tissue infections. Ann Surg. 1995; 221(5):558-563.

6. Anaya DA, McMahon K, Nathens AB, Sullivan SR, Foy H, Bulger E. Predictors of mortality and limb loss in necrotizing soft tissue infections. Arch Surg. 2005;140(2):151-157.

7. Khanna AK, Tiwary SK, Kumar P, Khanna R, Khanna A. A case series describing 118 patients with lower limb necrotizing fasciitis. Int $J$ Low Extrem Wounds. 2009;8(2):112-116.

8. Awsakulsutthi S. A retrospective review of necrotizing fasciitis in Thammasat University Hospital. J Med Assoc Thai. 2010;93 Suppl 7: S246-S253.

9. Hongladaromp C, Chareonsil B, Phadhana-Anake O. Predictors on mortality from necrotizng fasciitis in Sawanpracharak Hospital, Nakhonsawan, Thailand. Chiang Mai Med J. 2009;48(4):135-142.

10. Lancerotto L, Tocco I, Salmaso R, Vindigni V, Bassetto F. Necrotizing fasciitis: classification, diagnosis, and management. $J$ Trauma Acute Care Surg. 2012;72(3):560-566.

11. Stevens DL, Bisno AL, Chambers HF, et al. Practice guidelines for the diagnosis and management of skin and soft tissue infections: 2014 update by the Infectious Diseases Society of America. Clin Infect Dis. 2014;59(2):e10-e52.

12. Cainzos M, Gonzalez-Rodriguez FJ. Necrotizing soft tissue infections. Curr Opin Crit Care. 2007;13(4):433-439.

13. Rieger UM, Gugger CY, Farhadi J, et al. Prognostic factors in necrotizing fasciitis and myositis: analysis of 16 consecutive cases at a single institution in Switzerland. Ann Plast Surg. 2007;58(5):523-530.

14. Bair MJ, Chi H, Wang WS, Hsiao YC, Chiang RA, Chang KY. Necrotizing fasciitis in southeast Taiwan: clinical features, microbiology, and prognosis. Int J Infect Dis. 2009;13(2):255-260.

15. Salcido RS. Necrotizing fasciitis: reviewing the causes and treatment strategies. Adv Skin Wound Care. 2007;20(5):288-293.

16. Astorino T, Genrich I, MacGregor L, Victor CS, Eckhouse DR, Barbour L. Necrotizing fasciitis: early detection may save your patient's limb. Orthop Nurs. 2009;28(2):70-76.

17. Bucca K, Spencer R, Orford N, Cattigan C, Athan E, McDonald A. Early diagnosis and treatment of necrotizing fasciitis can improve survival: an observational intensive care unit cohort study. ANZ J Surg. 2013;83(5): $365-370$

18. Varma R, Stashower ME. Necrotizing fasciitis: delay in diagnosis results in loss of limb. Int J Dermatol. 2006;45(10):1222-1223.

19. Hsiao CT, Weng HH, Yuan YD, Chen CT, Chen IC. Predictors of mortality in patients with necrotizing fasciitis. Am J Emerg Med. 2008; 26(2):170-175.

20. Tunovic E, Gawaziuk J, Bzura T, Embil J, Esmail A, Logsetty S. Necrotizing fasciitis: a six-year experience. J Burn Care Res. 2012;33(1):93-100.
21. Nakayama J, Busse R. An analysis of vulvar necrotizing fasciitis in the unique and ethnically diverse Hawaiian population. Hawaii Med J. 2010;69(1):13-16.

22. Falkel JE. Amputation as a consequence of diabetes mellitus. An epidemiological review. Phys Ther. 1983;63(6):960-964.

23. Ruiz-Tovar J, Cordoba L, Devesa JM. Prognostic factors in Fournier gangrene. Asian J Surg. 2012;35(1):37-41.

24. Tilkorn DJ, Citak M, Fehmer T, et al. Characteristics and differences in necrotizing fasciitis and gas forming myonecrosis: a series of 36 patients. Scand J Surg. 2012;101(1):51-55.

25. Tiwari AK, Lal R. Study to evaluate the role of severity stratification of skin and soft tissue infections (SSTIs) in formulating treatment strategies and predicting poor prognostic factors. Int J Surg. 2014;12(2): $125-133$.

26. Steckel H, Baums MH, Tennstedt-Schenk C, Klinger HM. Necrotizing fasciitis of the knee following primary total knee arthroplasty. Knee Surg Sports Traumatol Arthrosc. 2011;19(12):2076-2079.

27. Puvanendran R, Huey JC, Pasupathy S. Necrotizing fasciitis. Can Fam Physician. 2009;55(10):981-987.

28. Elliott DC, Kufera JA, Myers RA. Necrotizing soft tissue infections. Risk factors for mortality and strategies for management. Ann Surg. 1996;224(5):672-683.

29. Dos Santos VP, da Silveira DR, Caffaro RA. Risk factors for primary major amputation in diabetic patients. Sao Paulo Med J. 2006;124(2): 66-70.

30. American Diabetes Association. Standards of medical care in diabetes 2007. Diabetes Care. 2007;30 Suppl 1:S4-S41.

31. Pomposelli JJ, Baxter JK 3rd, Babineau TJ, et al. Early postoperative glucose control predicts nosocomial infection rate in diabetic patients JPEN J Parenter Enteral Nutr. 1998;22(2):77-81.

32. Gurlek A, Firat C, Ozturk AE, Alaybeyoglu N, Fariz A, Aslan S. Management of necrotizing fasciitis in diabetic patients. J Diabetes Complications. 2007;21(4):265-271.

33. Rangaswamy M. Necrotizing fasciitis: a 10-year retrospective study of cases in a single university hospital in Oman. Acta Trop. 2001;80(2): $169-175$.

34. Oncul O, Erenoglu C, Top C, et al. Necrotizing fasciitis: a life-threatening clinical disorder in uncontrolled type 2 diabetic patients. Diabetes Res Clin Pract. 2008;80(2):218-223.

35. Bosch X, Poch E, Grau JM. Rhabdomyolysis and acute kidney injury. N Engl J Med. 2009;361(1):62-72.

36. Mendelssohn DC, Barrett BJ, Brownscombe LM, et al. Elevated levels of serum creatinine: recommendations for management and referral. CMAJ. 1999;161(4):413-417.

37. Dorner TE, Schwarz F, Kranz A, Freidl W, Rieder A, Gisinger C. Body mass index and the risk of infections in institutionalised geriatric patients. Br J Nutr. 2010;103(12):1830-1835.

38. Stevens DL, Bisno AL, Chambers HF, et al. Practice guidelines for the diagnosis and management of skin and soft-tissue infections. Clin Infect Dis. 2005;41(10):1373-1406.

39. Arcavi L, Benowitz NL. Cigarette smoking and infection. Arch Intern Med. 2004;164(20):2206-2216.

40. Lee TC, Carrick MM, Scott BG, Hodges JC, Pham HQ. Incidence and clinical characteristics of methicillin-resistant Staphylococcus aureus necrotizing fasciitis in a large urban hospital. Am J Surg. 2007;194(6): 809-812.

41. Wong CH, Khin LW, Heng KS, Tan KC, Low CO. The LRINEC (Laboratory Risk Indicator for Necrotizing Fasciitis) score: a tool for distinguishing necrotizing fasciitis from other soft tissue infections. Crit Care Med. 2004;32(7):1535-1541.

42. Knaus WA, Draper EA, Wagner DP, Zimmerman JE. APACHE II: a severity of disease classification system. Crit Care Med. 1985;13(10): $818-829$. 


\section{Publish your work in this journal}

The International Journal of General Medicine is an international, peer-reviewed open-access journal that focuses on general and internal medicine, pathogenesis, epidemiology, diagnosis, monitoring and treatment protocols. The journal is characterized by the rapid reporting of reviews, original research and clinical studies across all disease areas.

A key focus is the elucidation of disease processes and management protocols resulting in improved outcomes for the patient. The manuscript management system is completely online and includes a very quick and fair peer-review system. Visit http://www.dovepress.com/ testimonials.php to read real quotes from published authors.

Submit your manuscript here: http://www.dovepress.com/international-journal-of-general-medicine-journal 